\title{
Beau's Lines after Chemotherapy for ALL
}

\author{
Isao Miyoshi, Tetsuya Kubota and Hirokuni Taguchi
}

Key words: Beau's lines, chemotherapy, acute lymphoblastic leukemia

\section{(DOI: 10.2169/internalmedicine.46.6095)}

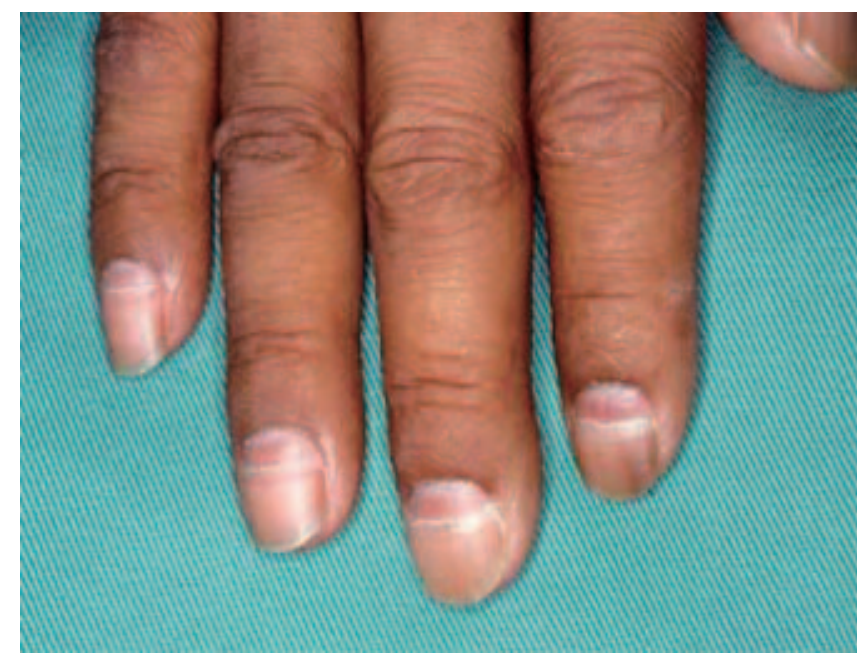

Figure 1. Fingernails showing prominent Beau's lines after chemotherapy.

A 38-year-old man was transferred to our hospital for suspicion of acute leukemia. On admission, his hemoglobin was $9.8 \mathrm{~g} / \mathrm{dl}$, the white cell count was $4,100 / \mathrm{mm}^{3}$ with $38 \%$ blasts, and the platelet count was $16,000 / \mathrm{mm}^{3}$. A bone marrow aspirate contained $92 \%$ blasts that were negative for peroxidase. He was diagnosed with acute lymphoblastic leukemia (L2). Immediately, he received induction chemotherapy consisting of doxorubicin, vincristine, L-asparaginase, and prednisolone over a 2 -week period. This resulted in a complete remission, although he had severe oral mucositis and total alopecia. The so-called Beau's lines were noted on all of his fingernails as shown in Fig. 1, which was photographed 12 weeks after completion of the chemotherapy. His toenails also showed similar transverse lines. Beau's lines (transverse depressions of the nails) occur in various conditions such as cancer chemotherapy, acute debilitating illnesses, and hypoxia at high altitude or deep sea. They reflect temporary cessation of nail matrix formation. The nail damage does not appear on the nail plate until 6-8 weeks after the insult, it moves distally with the growth of the nail and is lost at about 6 months.

\footnotetext{
(C) 2007 The Japanese Society of Internal Medicine http://www.naika.or.jp/imindex.html
} 